\section{High-flying Reading dentist}

Kiran Shankla is a 2021 recipient of the British Dental Association's (BDA's) Certificate of Merit for Services to the Association. Kiran, who graduated from the University of Birmingham in 2013, is Chair of the BDA Reading Section and a GDP with a specialist interest in restorative dentistry.

\section{Where are you based?}

I spent the early years of my life in West London before moving to Reading at the age of 12. I have been living in Reading on/ off for the last 19 years. It is currently my hometown and where I envisage myself living for many years to come.

\section{What attracted you to dentistry originally?}

When I was younger, I had really crowded teeth with a displaced canine. I have no photos of me smiling up until I finished my orthodontic treatment. A simple treatment made a huge impact on my life and that was something I hoped to give to others. Alongside all the other benefits of normal working hours, being able to work part-time appealed, and being able to travel the world with my degree.

\section{Can you outline your career history and} places of work?

Dental Foundation Training - Smile Dental, Slough 2013-2014

Dental Core Training - Bloxham Dental, Banbury 2014-2015

Associate positions:

1300 Smiles - Australia 2015-2016

Wood Lane Dentistry 2016-present

Blandy House 2020-present.

\section{What appealed to you about restorative} dentistry in particular?

I knew early on in my career I wanted to pursue further training; however, I was unsure which route to go down. After starting at Wood Lane Dentistry and shadowing how my principal worked, I was encouraged to start a part-time master's. I chose UCL Eastman for its world-renowned reputation, wide variety of speakers and part-time flexibility.
I thoroughly enjoyed the four years, and it has had a huge impact on how I work today. It significantly improved my confidence and treatment planning larger cases. Restorative dentistry is the bread and butter of all dentistry, and it is my aim to become as good as I can at it.

Do you plan to specialise further in the future?

I completed a four-year part-time Restorative MSc at UCL Eastman in 2020. I was fortunate enough to get my dissertation published internationally in the Journal of Dentistry. For now, I am focusing on implementing everything I have learnt into practice, but I am a course junkie and regularly attend lots of CPD events.

\section{How do you spend a typical week?}

I currently have Mondays off which I spend getting through all my admin work and going for nice long walks. Occasionally I help teach on the Certificate year of the Restorative MSc at UCL Eastman.

The rest of the week is split across two practices: I work as a general dentist at Wood Lane Dentistry Tuesday-Thursday and on restorative referral at Blandy House on Friday.

\section{How has the pandemic affected you workwise? \\ Initially, it was tough trying to} understand and negotiate all the new rules and PPE requirements. However, as time has gone on, I have adapted and now find it is part of my daily routine, but I can't wait to stop wearing FFP3 masks!

Why did you decide to get involved with the BDA Reading Section?

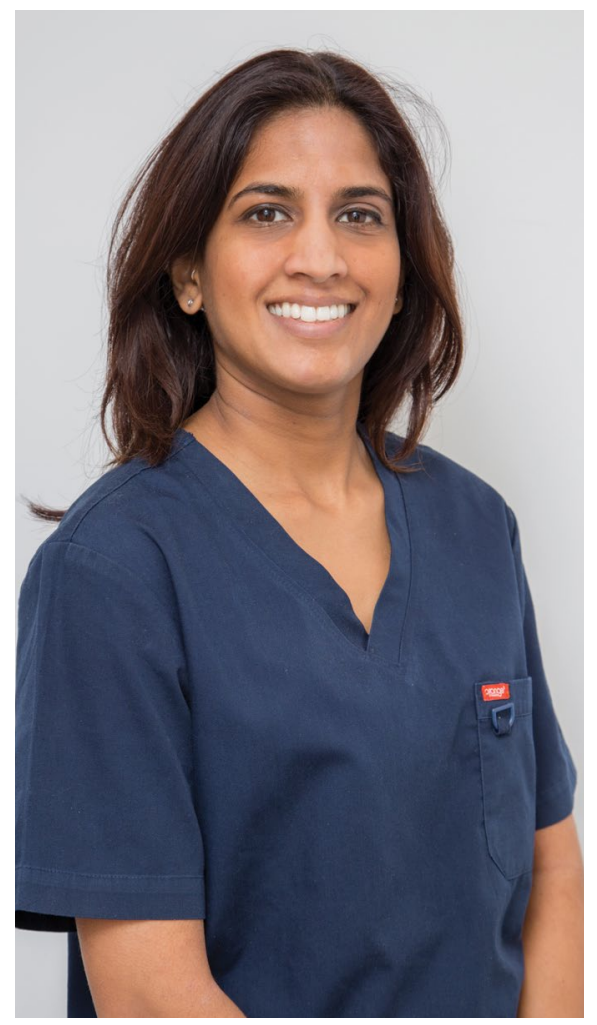

I initially started attending evening events when I moved back from Australia to meet local colleagues. After a year, I was asked to become a committee member as more younger dentists were wanted. It was a great opportunity to network with local dentists, help meet well-established speakers and get more involved with my profession in a non-clinical role.

What political/other activities are you or have you been involved with outside your day job to date?

Lecturing/teaching:

- Key Opinion Leader - DMG

- Eastman Dental Institute, 2021 - parttime visiting lecturer helping teach on the Restorative Dental Practice MSc

- International Congress of Dentistry, April and November 2021 - a general dental conference attended by dentists based in South Asia. A keynote speaker on ICON infiltration

- Wood Lane Study club - in-house speaker and organiser of Wood Lane Dentistry study club. A local study club held in house giving lectures on various topics. Topics include but not exclusive to: facebows, ICON Resin Infiltration etc. 
« Committees:

- BACD full member, 2021

- International Awards of Excellence and British Dental Awards Judging Panel, 2021

- BDA Reading Chair, April 2019October 2021

- BDA Reading committee member, June 2016-present

- $2^{\text {nd }}, 3^{\text {rd }}$ and $5^{\text {th }}$ year dental school representative, Birmingham 2009-2013.

Charitable activities:

- STEM Ambassador, 2020-present

- Brightside mentor, 2018-present. A social mobility charity helping disadvantaged students.

An impressive list! Why do you think you were nominated for the BDA award?

Honestly, I'm not sure as there are lots of charitable dentists in the country. I think it may have been due to being one of the youngest chair representatives the committee has had and being the only current woman on the committee. I also provide mentorship to underprivileged A-level students hoping to apply for dentistry.

\section{How did it feel to win?}

It was a big surprise as I was not aware this award existed. I am extremely grateful and humbled to have been recognised for my hard work and contributions I have made to the profession in the early years of my career.

The award ceremony will be taking place in 2022, I can't wait!

Any future plans you'd like to share, career or otherwise?

I am getting married in spring 2022 so most of my free time has been taken up by that. When I'm not carrying out wedmin, I post on my dental Instagram @Shanklasmiles to help share tips and tricks with my colleagues.

The BDA's Honours and Awards are designed to acknowledge the unsung heroes of our profession; those who have upheld and improved the standards of dentistry. For more information and to nominate someone for an award in 2022, visit https://www.bda.org/about-the-bda/ honours-and-awards/Pages/default.aspx.

\section{A special event to celebrate the life of Professor Jimmy Steele CBE}

By Professor Justin Durham

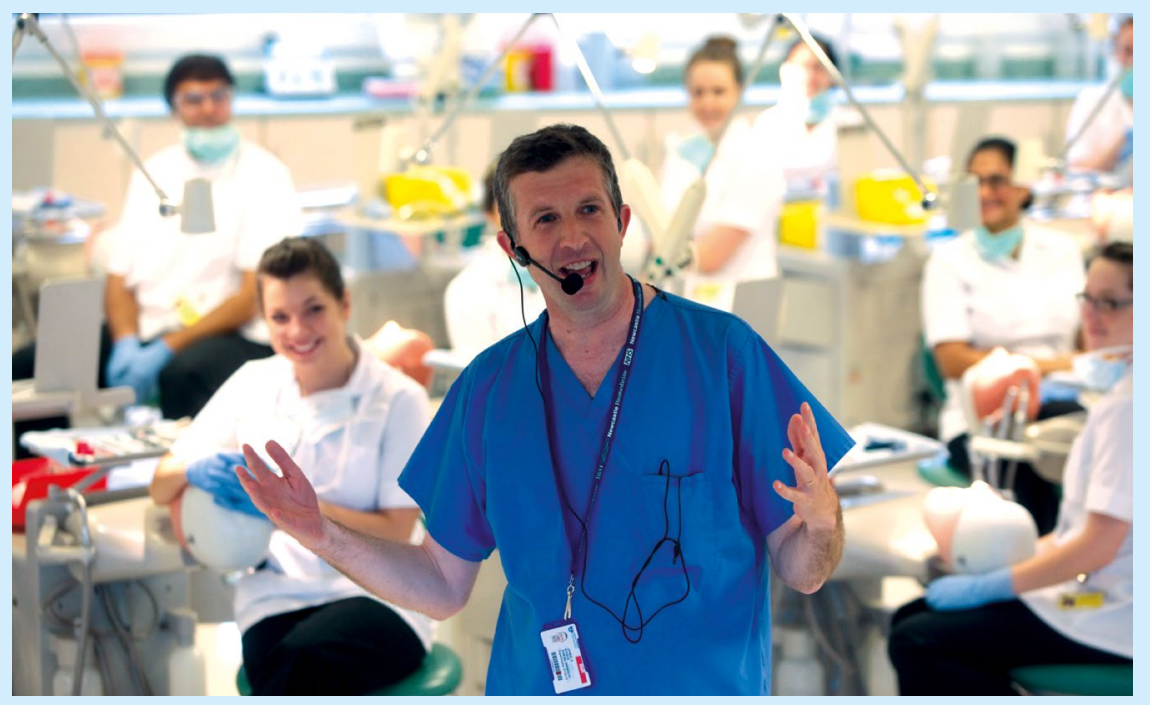

Join us for a very special event to celebrate the life of an exceptional Head of School and Professor of Oral Health Services Research, Jimmy Steele CBE (pictured).

Professor Jimmy Steele's research included work in primary care, clinical trials, health economics and quality of life measurement and he authored or contributed to several books in areas such as restorative and preventative dentistry.

He was extremely passionate about discussing the big issues we face in dentistry and as such we have brought together four experts in oral health inequalities to continue those conversations.

Please join us for the first Conversations of Steele on Monday 31 January 2022 at 18:00 GMT. We welcome you to watch and comment on an insightful and inspiring conversation on oral health inequalities between our experts:

- Professor Sarah Baker, University of Sheffield,

- Professor Barry Gibson, University of Sheffield

- Dr Vanessa Muirhead, Queen Mary University of London

- Professor Murray Thomson, University of Otago.

We will also highlight the Jimmy Steele Scholarship with a special introduction from Jimmy's wife, Professor Katie Bushby.

To book on this event please go to https:// www.ncl.ac.uk/dental/about/events/.

\section{Reference}

1. Murray J, Thomason J M. James George Steele CBE. Br Dent J 2018; 225: 388.

\section{CGDent notice}

An advert for FGDP(UK) was published in error in the 26 November 2021 issue of the BDJ.

On 1 August 2021, the membership and activities of FGDP(UK) transferred from The Royal College of Surgeons of England to the College of General Dentistry (CGDent).

CGDent is now the professional home for the whole dental team and so FGDP(UK) no longer exists. We apologise for the confusion this incorrect advert will inevitably have caused.

CGDent embraces and supports general practice and wider primary care dentistry, and continues to provide standards and guidance for the profession. For more information and to join CGDent, visit their website: https://cgdent.uk/join/. 